\title{
Assessment of potential impacts associated with gene flow from transgenic hybrids to Mexican maize landraces
}

\author{
Bill Duncan (1D) Elisa Leyva-Guerrero • Todd Werk • Duška Stojšin • \\ Baltazar M. Baltazar · Silverio García-Lara • Mariana Zavala-López • \\ Juan Manuel de la Fuente-Martínez · Chen Meng
}

Received: 11 March 2019/Accepted: 22 June 2019/Published online: 27 June 2019

(C) The Author(s) 2019

\begin{abstract}
Genetically modified (GM) maize has been grown and safely consumed on a global scale since its commercialization in 1996. However, questions have been raised about the potential impact that GM maize could have on native maize landraces in Mexico, which is the center of origin and diversity of maize. This research was conducted to evaluate potential changes to maize landraces in an unlikely event of transgene introgression. For this study, two GM traits that confer insect protection and herbicide tolerance in maize (MON 89034 and MON 88017), designated as VT3Pro, were introgressed into two Mexican landraces, Tuxpeño and Tabloncillo. Field trials were conducted across four environments to
\end{abstract}

Electronic supplementary material The online version of this article (https://doi.org/10.1007/s11248-019-00160-3) contains supplementary material, which is available to authorized users.

B. Duncan $(\varangle) \cdot$ E. Leyva-Guerrero ·

T. Werk · D. Stojšin · B. M. Baltazar · C. Meng

Bayer Company, 700 Chesterfield Pkwy. West, St. Louis, MO 63017, USA

e-mail: bill.duncan@bayer.com

S. García-Lara · M. Zavala-López

Tecnológico de Monterrey, Escuela de Ingeniería y

Ciencias, Monterrey, Mexico

J. M. de la Fuente-Martínez

Bayer Company, Park Plaza Torre II, 504 Javier Barros

Sierra Ave., Col. Santa Fe, Del. Alvaro Obregon,

CP 01210 Mexico, DF, Mexico assess phenotypic characteristics, plant response to stressors, and kernel composition of landraces with and without VT3Pro traits. Furthermore, materials from four backcrossing generations were analyzed for segregation of these GM traits. Generally, no significant differences were observed between landraces with and without VT3Pro traits for the evaluated characteristics and the segregation analysis showed that GM traits, when introgressed into landraces, followed Mendelian principles. These results support the conclusion that, if inadvertently introgressed into landraces, VT3Pro traits are not expected to alter phenotypic or kernel characteristics, plant response to stressors (except for targeted insect protection and herbicide tolerance traits) and would segregate like any endogenous gene. These results should be taken into consideration when discussing benefits and risks associated with commercial production of GM maize hybrids in the centers of origin and diversity of maize.

Keywords Maize landraces · Gene flow · GM traits · VT3Pro maize

\section{Introduction}

Maize is an important crop grown over geographically diverse regions, climates, and soil types (Shiferaw et al. 2011). The global production of maize surpasses production of any other crop, having increased 5-fold 
over the past 56 years (FAOSTAT 2016). This remarkable increase in maize productivity is due to advances in agronomic practices, as well as advances in maize genetics like replacement of open-pollinated populations with maize hybrids and the introduction of biotechnology traits (Troyer 2006).

In 1996, genetically modified (GM) maize became commercially available in the United States. Since then, farmers around the world have rapidly adopted GM maize. In 2015, GM maize constituted a large portion of maize planted in the USA $(92 \%)$, Brazil $(88 \%)$, and Argentina (78\%) with a total of 60.6 million hectares grown worldwide (ISAAA 2016). Almost all GM maize planted globally contains insect protection and herbicide tolerance traits, either as single transgenes or stacked combination (ISAAA 2016). These and other GM traits have contributed to delivering higher yield, reducing chemical pesticide use, and increasing profitability (Brookes and Barfoot 2018a, b).

The food, feed, and environmental safety of GM maize, as well as their benefits to society, have been demonstrated by global cultivation and consumption of GM maize for over two decades and by studies that showed phenotypic, ecological, and compositional equivalence of GM and conventional crops (Corrales et al. 2018; Phipps and Park 2002; Horak et al. 2007; Drury et al. 2008; Harrigan et al. 2009; Ridley et al. 2011; Sammons et al. 2014; Nakai et al. 2015; Horak et al. 2015a, b; ISAAA 2016; Heredia-Diaz et al. 2016). However, in spite of food, feed, and environmental safety record of GM crops, there remains some hesitation to accepting biotechnology products (ISAAA 2016) and questions have been raised regarding the potential impact that commercial cultivation of GM crops might have in regions where native landraces are traditionally grown by farmers.

Mexico is the center of origin and genetic diversity of maize (Matsuoka et al. 2002). Here, maize remains an important staple crop with economic and cultural value (Espinosa et al. 2003), covering 28\% of the total agricultural area (SAGARPA 2017) and yielding on average $3.7 \mathrm{t} / \mathrm{ha}$ (FAOSTAT 2016). To meet the national demand, a third of maize consumed in Mexico, totaling over 14 million tons in 2015, comes from import (FIRA 2016).

Of the 7.5 million hectares of maize grown annually in Mexico (FAOSTAT 2016), approximately twothirds are planted with open-pollinated landraces
(Espinosa et al. 2003), which are dynamic populations that are genetically diverse, locally adapted, and have distinct identities. Maize landraces have been selected and maintained via traditional farming systems that, on one hand, maintain the attributes deemed valuable by farmers, like ear and kernel characteristics (Louette and Smale 1998), but on the other hand allow for gene transfer from other landraces, improved maize varieties, or even teosinte (Castillo Gonzalez and Goodman 1995; Louette and Smale 1998; Baltazar et al. 2005; Wang et al. 2017).

A total of 59 races of Mexican maize have been identified based on their molecular and morphological characteristics (Sanchez et al. 2000). Two of the more important landraces, Tuxpeño and Tabloncillo (Sanchez et al. 2000), were evaluated in this study. Landraces of the Tuxpeño type originated from tropical regions of low to medium elevation (Sanchez et al. 2000) and have been widely grown across different states such as Oaxaca, Baja California, Chiapas, Sinaloa, Chihuahua, Sonora, Colima, Durango, Nayarit, Nuevo Leon, Tamaulipas, Hidalgo, Jalisco, Morelos, Puebla, Chiapas, and Yucatan (Aragon-Cuevas et al. 2005; Brush 1995; Louette and Smale 1998; Ortega Paczka 1973; Pineda-Hidalgo et al. 2014; Vazquez-Carrillo et al. 2017; Lazos and Chauvet 2012). The Tuxpeño type landraces are characterized by having cylindrical ears with 12-16 rows of kernels (Sanchez et al. 2000), shorter plant stature, higher yield (Brush 1995), later flowering, large number of tassel branches, white kernels (Baltazar et al. 2005), smaller seed size, and high crude fiber content in grain (Vazquez-Carrillo et al. 2017). Even though their main usage has been for tortilla making, because of their low price and wide availability, they have also been used for specialty products such as pozoles (Vazquez-Carrillo et al. 2017), elotes, botanas, or atoles (Fernandez-Suarez et al. 2013). Furthermore, Tuxpeño type landraces have been used in breeding programs, not only in Mexico, but worldwide (Sanchez et al. 2000).

The Tabloncillo type landraces originated in western Mexico at mid elevations and along the Pacific coastal plains of northwestern Mexico (Sanchez et al. 2000) and have been grown in different states such as Sonora, Jalisco, Sinaloa, Baja California, Chihuahua, Colima, Nayarit, and Guanajuato (Vazquez-Carrillo et al. 2017; Louette and Smale 1998; Pineda-Hidalgo et al. 2014; Lazos and Chauvet 2012). Tabloncillo 
landraces are characterized by shorter plant stature, earlier maturity, predominantly white kernels (Louette and Smale 1998), longer ears with 8-10 rows of kernels (Sanchez et al. 2000), earlier flowering, fewer tassel branches (Baltazar et al. 2005), larger kernels, low grain expansion volume, high grain protein, and high ash content in grain (Vazquez-Carrillo et al. 2017). They have been typically used for specialty food products like pozoles (Sanchez et al. 2000; Vazquez-Carrillo et al. 2017), pinoles, elotes, botanas, or piznates, but can be used for tortilla making as well (Fernandez-Suarez et al. 2013).

Mexican maize landraces are genetically dynamic populations as they are typically grown in proximity to other landraces or improved varieties to increase cross-pollination among them and allow for selection based on farmer's preference and use (Louette and Smale 1998; Castillo-Gonzalez and Goodman 1995). This style of traditional farming, a process called "creolization", allows for the influx of genes into landraces and often includes incorporation of favorable characteristics mostly from improved varieties (Bellon and Berthaud 2004). For example, it was estimated that one third of Tuxpeño landraces showed introgression of genes from improved hybrid varieties (Ortega-Paczka 1973). For the most part, this intentional incorporation of genes from improved varieties has not lead to a dramatic displacement of landraces but resulted in the coexistence of improved varieties and Mexican landraces (Bellon and Berthaud 2004).

In contrast to substantial incorporation of genes from conventional, improved varieties into landraces, there has been evidence of no or limited presence of transgenes into local landraces via seed mixtures or gene flow (Ortiz-Garcia et al. 2005). All indications suggest that landraces are being replaced to a greater extent by industrialization and urbanization of arable land, rather than by modern maize varieties (Chambers et al. 2007).

Because of the unique genetics and cultural importance of landraces in the center of origin of maize, this study was conducted to evaluate the impact that introgression of GM traits into maize landraces may have on their phenotypic and kernel compositional characteristics, responses to stressors, and transgene segregation within a landrace.

\section{Materials and methods}

Development of study materials

Two landrace accessions, Tuxpeño (PI 583894) from Sonora and Tabloncillo (PI 490927) from Nayarit, were acquired in 2012 from the National Plant Germplasm System (NPGS) of the United States Department of Agriculture (USDA). They were chosen as they represent two of 59 recognized races of Mexican landraces with diverse origin, phenotype, and utilization (Sanchez et al. 2000; Fernandez-Suarez et al. 2013).

These landraces were crossed with a maize inbred line that contained two GM traits, MON 89034 and MON 88017 developed by Monsanto Company (St. Louis, MO, USA). The MON 89034 transgene, produces two insecticidal proteins (Cry1A.105 and Cry2Ab2) that protect against feeding damage caused by several lepidopteran insect pests. Cry1A.105 is a modified Bacillus thuringiensis (Bt) Cry1A protein and Cry $2 \mathrm{Ab} 2$ is a $B t$ (subsp. kurstaki) protein.

The MON 88017 transgene produces a modified Bt (subsp. kumamotoensis) Cry3Bb1 protein that protects against corn rootworm larval feeding. In addition, MON 88017 produces a protein (5-enolpyruvylshikimate-3-phosphate synthase) from Agrobacterium sp. strain CP4 (CP4 EPSPS), which confers tolerance to glyphosate, the active ingredient in the Roundup ${ }^{\circledR 1}$ family of agricultural herbicides.

The maize commercial product designated as VT3Pro, was developed by traditional breeding via crossing lines with MON 89034 and MON 88017. In this study, introgression of VT3Pro traits into the two landraces was conducted through traditional backcrossing and phenotypic selection in Puerto Rico, USA during the 2013-2015 period. Three backcross generations, using landraces as recurrent parents were completed to create materials with over $94 \%$ landrace genetics. During backcrossing, population size of each recurrent parent was on average 350 plants to maintain the genetic diversity of individuals within each landrace. The $\mathrm{BC} 3$ generation was sib-pollinated to produce sub-populations with and without the VT3Pro traits. During each cycle of backcrossing $(\mathrm{BC} 1, \mathrm{BC} 2$, and $\mathrm{BC} 3$ ), the presence of VT3Pro traits was ensured

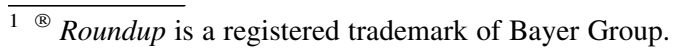


by herbicide application and molecular-based assays. During sib-pollination (BC3F2), the presence or absence of VT3Pro traits was determined by transgene zygosity testing. Progeny determined to be homozygous positive for both traits were sib-pollinated and the bulked seed was used as Tuxpeño VT3Pro and Tabloncillo VT3Pro entries in the field trials (Table 1). Similarly, progeny determined to be homozygous negative for both traits were sib-pollinated and bulked seed was used as Tuxpeño control and Tabloncillo control entries in the field trails (Table 1).

Additional landrace accessions, acquired in 2012 from the NPGS, were included in the field trials as reference materials to represent the range of variability typical for landraces grown in Mexico. The source seed for each reference entry used in this study was produced by sib-pollination in 2015 in the same nursery as the test and control materials. As genetic variability of Mexican landraces is associated mostly by region of their origin (Arteaga et al. 2016), these reference landraces were chosen to represent races from the Mexican states of Sonora, Chihuahua, Sinaloa, Nayarit, Jalisco, Guanajuato, and Puebla.
The selected landrace references were: Tabloncillo Nayarit 63 (PI 515340), Tuxpeño Sonora 51 (PI 479072), Celaya 9 (PI 484677), Jala (PI 484692), Chalqueño (PI 485074), Vandeño/Bandeño (PI 489509), Onaveño (PI 474210), Blando/Blandito (PI 583893), Conico Norteño (PI 484473), and Harinoso 8 (PI 490975). Most of the reference landraces had intermediate kernel hardness but ranged from hard for Conico Norteño to soft for Harinoso 8 and very soft for Blando/Blandito, as per Vazquez-Carrillo et al. (2017) classification. Due to diversity of their kernel characteristics, these landraces have been used in traditional Mexican cuisine differently, such as for making tortillas (Tuxpeño, Tabloncillo, Celaya, Valndeño, and Onaveño), atoles (Blando and Harinoso 8), pinoles (Chalqueño, Jala, and Conico), botanas (Vandeño), or pozoles (Jala and Blando) (Fernandez-Suarez et al. 2013).

\section{Field observations}

Field trials were grown in two USA states (Arizona and Texas) across 2 years (2015 and 2016). These four environments are designated as AZ-2015, TX-2015,

Table 1 Descriptive characteristics of landraces evaluated in 2015 and 2016 field trials

\begin{tabular}{|c|c|c|c|c|c|c|}
\hline Landrace entries & $\begin{array}{l}\text { Plant Inventory } \\
\text { number }^{\mathrm{a}}\end{array}$ & $\begin{array}{l}\text { Origin within } \\
\text { Mexico }\end{array}$ & $\begin{array}{l}\text { Kernel } \\
\text { hardness }^{\text {b }}\end{array}$ & $\begin{array}{l}\text { Tassel color }(\%) \\
\text { (white:red) }\end{array}$ & $\begin{array}{l}\text { Cob color }(\%) \\
\text { (white:red) }\end{array}$ & $\begin{array}{l}\text { Kernel color }(\%) \\
\text { (white:with } \\
\text { yellow:with red) }\end{array}$ \\
\hline Tuxpeño VT3Pro & PI 583894 & Sonora & Intermediate & $67.8: 32.2$ & $99.7: 0.3$ & 90.3:9.7:0.0 \\
\hline Tuxpeño control & PI 583894 & Sonora & Intermediate & $60.0: 40.0$ & 100.0:0.0 & $82.7: 15.4: 1.9$ \\
\hline Tabloncillo VT3Pro & PI 490927 & Nayarit & Intermediate & $85.6: 14.4$ & $99.4: 0.6$ & $75.9: 22.5: 1.6$ \\
\hline Tabloncillo control & PI 490927 & Nayarit & Intermediate & 81.1:18.9 & 100.0:0.0 & $76.5: 21.9: 1.6$ \\
\hline Tuxpeño Sonora 51 & PI 479072 & Sonora & Intermediate & $84.1: 15.9$ & 100.0:0.0 & $70.9: 27.5: 1.6$ \\
\hline Tabloncillo Nayarit 63 & PI 515340 & Nayarit & Intermediate & $84.1: 15.9$ & $98.4: 1.6$ & $61.9: 32.5: 5.6$ \\
\hline Conico Norteño & PI 484473 & Chihuahua & Hard & 81.9:18.1 & 100.0:0.0 & $36.5: 61.3: 2.3$ \\
\hline Harinoso 8 & PI 490975 & Sonora & Soft & $85.6: 14.4$ & $85.3: 14.7$ & $73.4: 25.3: 1.3$ \\
\hline Onaveño & PI 474210 & Sonora & Intermediate & $62.5: 37.5$ & $97.5: 2.5$ & 88.8:11.2:0.0 \\
\hline Blando/Blandito & PI 583893 & Sinaloa & Very soft & $28.8: 71.2$ & $84.0: 16.0$ & 88.0:0.0:12.0 \\
\hline Celaya 9 & PI 484677 & Guanajuato & Intermediate & 71.9:28.1 & 100.0:0.0 & 99.4:0.0:0.6 \\
\hline Jala & PI 484692 & Jalisco & Intermediate & $68.8: 31.2$ & $85.0: 15.0$ & $91.2: 7.5: 1.3$ \\
\hline Chalqueño & PI 485074 & Puebla & Intermediate & $88.1: 11.9$ & $93.6: 6.4$ & 53.9:39.0:7.1 \\
\hline Vandeño/Bandeño & PI 489509 & Nayarit & Intermediate & $58.8: 41.2$ & 100.0:0.0 & $3.7: 95.0: 1.3$ \\
\hline
\end{tabular}

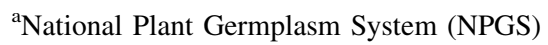

${ }^{\mathrm{b}}$ Kernel hardness per Vazquez-Carrillo et al. (2010)

${ }^{\mathrm{c}}$ Proportion of ears with white kernels only, with yellow kernels (yellow or white/yellow), and with red kernels (red, red/white, red/ yellow) 
AZ-2016, and TX-2016 (S-Table 1). The trials were planted either during the fall of 2015 or in the spring of 2016 representing two cultivation cycles with distinct growing conditions typical for maize farming systems utilized in Mexico (Louette and Smale 1998). The experiments were set in a randomized complete block design with four replications. Selected sites represented three distinct ecoregions (Madrean Archipelago, Sonoran Desert, and Western Gulf Coastal Plain) found in both southern USA and northern Mexico (Wiken et al. 2011). Furthermore, these field sites in southern USA regions were selected because they are congruent with regions (such as Baja California, Sonora, and Tamaulipas) where landraces, including Tuxpeño and Tabloncillo, are grown in Mexico (Lazos and Chauvet 2012).

Of a total of 14 entries evaluated in this study (Table 1), 10 were planted per site. Entries Tuxpeño VT3Pro, Tuxpeño control, Tabloncillo VT3Pro, Tabloncillo control, Tuxpeño Sonora 51, Tabloncillo Nayarit 63, Conico Norteño, and Harinoso 8 were planted at all sites. Onaveño and Blando/Blandito were planted at AZ-2016 only, Celaya 9 at AZ-2015 and TX-2016, Chalqueño at TX-2015 and TX-2016, Jala at AZ-2015, and Vandeño/Bandeño at TX-2015.

The entries were planted in eight-row plots that varied in size from 33.6 to $37.2 \mathrm{~m}^{2}$ depending on site. To ensure a uniform stand, plant thinning was conducted early in the season at all four sites. Agronomic practices (e.g., irrigation, fertilizers, pesticides) throughout the season were those typical to each region, and all maintenance operations were performed uniformly across plots. Protection against targeted pests was employed where necessary so that VT3Pro entries did not have advantage compared to control and reference landraces.

\section{Phenotypic characteristics}

To assess the diversity of landraces in the study, three descriptive characteristics were evaluated including colors of tassels, cobs, and kernels (Table 1). Tassel color was evaluated during anthesis on 20 representative plants per replication and was defined as white or red (any shade). Color of the cobs and kernels were evaluated at harvest on 20 ears per replication. Cob color was either white or red. Ears were evaluated for kernel color as those with white kernels (all white), those with yellow kernels (all yellow or white and yellow), or ears with red kernels (all red, red and white, or red and yellow).

In addition to the three descriptive characteristics, a total of 22 phenotypic characteristics were evaluated to assess if there are differences between landraces with and without VT3Pro traits (S-Table 2). The evaluated characteristics included: early and final stand count, days to anthesis and silking, stay-green, ear and plant height, dropped ears, stalk and root lodging, test weight, grain moisture, 100-kernel weight, and yield. These characteristics are typically assessed by breeders, agronomists, and/or risk assessors for determining the potential impact of GM traits. Additional characteristics measured were: tassel length, number of tassel branches, ear length and diameter, kernel depth and number, cob diameter, and kernel rows per ear. They were assessed to better characterize the landraces used in this study and to include ear characteristics typically evaluated by Mexican farmers (Louette and Smale 1998). The evaluation was done using the inner rows of the eightrow plots.

\section{Responses to abiotic and biotic stressors}

Plant responses to stressors (i.e., interactions between the crop plants and their receiving environment) were used to compare landraces with and without VT3Pro traits. The focus was on plant responses to abiotic stressors, arthropod damage, and disease damage. Entries were evaluated at all sites four times during the season (at V6-V8, V12-VT, R1-R3, and onset of R6). The stressors were selected based on current activity causing plant injury in the field trial or likelihood of that injury to occur in maize during a given observation period. Both active or anticipated stressors often varied among observations at a site, as well as among the evaluated sites.

Stressor observations were collected from each plot using a categorical scale of increasing severity of plant damage (none, slight, moderate, severe). A plot was given the assessment of none during the evaluation of a stressor if no symptoms were observed. An observation of slight was given if the symptoms were not damaging to plant development (e.g., minor feeding or lesions) so that likely no mitigation was required. If a plot was given the score of moderate for a stressor, this was considered as intermediate between slight and severe-a situation that would likely require 
mitigation. Finally, an observation of severe was given if the symptoms from a stressor were damaging to plant development (e.g., stunting or death) such that mitigation would unlikely be effective.

Kernel compositional analysis

Kernel compositional analyses were conducted using harvested grain collected from each plot across the four tested environments. Grain samples were ground and homogenized prior to analyses that included proximate analytes, phenolic acids, and soluble carbohydrates. Proximate analytes were protein, total fat, ash, and carbohydrates (by calculation) following the methods described in Drury et al. (2008). Analyses were conducted at Covance Laboratories Inc. in Madison, WI, USA.

Phenolic acids were extracted from $50 \mathrm{mg}$ samples of ground homogenized kernels by an improved microscale method as described in Zavala-López and García-Lara (2017). Extracts were analyzed by HighPerformance Liquid Chromatography with DiodeArray Detection (HPLC-DAD) according to the method of Ayala-Soto et al. (2014) using an HPLC (Agilent 1100 Santa Clara, CA) coupled with a photodiode array (PDA) detector (Agilent G1315D, Santa Clara, CA). Linear gradient elution was performed with HPLC-grade water (acidified to $\mathrm{pH} 2$ with trifluoroacetic acid) and acetonitrile, at a flow rate of $0.6 \mathrm{~mL} / \mathrm{min}$ at $25^{\circ} \mathrm{C}$. Phenolic acids were separated on a Zorbax SB-Aq, $4.6 \mathrm{~mm}$ ID $\times 150 \mathrm{~mm}(3.5 \mu \mathrm{m})$ reverse phase column. Peak identification of transferulic acid and $p$-coumaric acid was based on the retention times of authentic standards (Sigma-Aldrich, St. Louis, MO, USA).

Measured soluble carbohydrates were sucrose, fructose, and glucose. Samples of $50 \mathrm{mg}$ of homogenized maize kernels were resuspended in $1 \mathrm{~mL}$ of distillated water and incubated at $25{ }^{\circ} \mathrm{C}$ for $15 \mathrm{~min}$ with constant agitation at $2500 \mathrm{rpm}$. Samples were then incubated overnight at $4{ }^{\circ} \mathrm{C}$. An additional $0.5 \mathrm{~mL}$ of distilled water was added to all samples followed by incubation at $25^{\circ} \mathrm{C}$ for $15 \mathrm{~min}$ with constant agitation at $2500 \mathrm{rpm}$. Samples were then centrifuged for $5 \mathrm{~min}$ at $6000 \mathrm{rpm}$, the supernatant was recovered and further centrifuged for $10 \mathrm{~min}$ at $13,000 \mathrm{rpm}$. The supernatant was recovered and filtered through a GHP $0.2 \mathrm{um}$ filter (Pall Life
Sciences, Ann Harbor, MI). Samples were analyzed within 24 hours.

Extracted sugars were analyzed by the method of Heredia-Olea et al. (2012) using an HPLC (Waters HPLC Breeze model, Milford, MA) equipped with a refractive index detector (Waters 2414 model, Milford, MA). The Empower software was used to process data and command the equipment. Sucrose, glucose, and fructose were separated using a Shodex SP0810 column $(300 \times 8.0 \mathrm{~mm})$ with a flow rate of $0.6 \mathrm{~mL} / \mathrm{min}$ of HPLC-grade water. The column, detector, and auto sampler temperatures were set at 80, 50, and $4{ }^{\circ} \mathrm{C}$, respectively. Standards (SigmaAldrich, St. Louis, MO, USA) of sucrose, fructose and glucose, were used for peak identification and quantification. Analyses of phenolics and soluble carbohydrates were conducted at Tecnológico de Monterrey (Monterrey, México).

Genetic segregation analysis

Segregation assessment of VT3Pro transgenes (MON 89034 and MON 88017) was conducted at the Monsanto research facilities in St. Louis, MO, USA. The backcrossed generations (BC1, BC2, BC3, and $\mathrm{BC} 3 \mathrm{~F} 2$ ) of Tuxpeño VT3Pro and Tabloncillo VT3Pro were evaluated to determine if MON 89034 and MON 88017 segregation follows Mendelian principles. Approximately 180 seeds of each generation per landrace were grown in a greenhouse. At early vegetative growth stage (V1-V4), leaf tissue from each seedling was sampled and gene presence was determined by event-specific polymerase chain reaction (PCR) analyses or by GeneCheck ${ }^{\circledR}$ immunoassays (Cry1Ab QuickStix Lateral Flow test strips, Roundup Ready QuickStix Lateral Flow test stripsEnvirologix Inc., Portland, ME, USA).

\section{Statistical analysis}

\section{Phenotypic and kernel compositional characterization}

Descriptive characteristics were expressed as a proportion of individuals representing different colors of tassels, cobs, and kernels. The data was summarized using descriptive statistics. For other phenotypic and kernel compositional characteristics, the data was statistically analyzed using a linear mixed model under a randomized complete block design with 
landraces designated as a fixed effect. Sites, blocks nested within site, and site-by-landrace interactions were designated as random effects. Pairwise comparisons were made within the linear mixed model analysis to compare the test materials (Tuxpeño VT3Pro and Tabloncillo VT3Pro) to the corresponding conventional counterparts (Tuxpeño control and Tabloncillo control, respectively) across sites. These comparisons were also conducted across landraces in order to evaluate performance of landraces with and without VT3Pro traits across germplasm. Furthermore, pairwise comparisons were made between Tuxpeño control and Tabloncillo control to assess differences between the two landrace accessions. The level of significance was set at 5\% $(\alpha=0.05)$. Data was interpreted in a step-wise process similar to that described in Horak et al. (2015a).

\section{Responses to abiotic and biotic stressors}

The qualitative data regarding plant response to abiotic stressors, arthropod damage, and disease damage are categorical. The assessments of the landraces with and without VT3Pro traits were considered different in susceptibility or tolerance if the range of injury symptoms did not overlap between the compared entries across all four replications at a site (Horak et al. 2015a). Any observed differences were assessed for biological significance in the context of the range of the landrace reference materials, and for consistency across other observation times and sites. The responses to environmental stressors were also conducted across landraces in order to evaluate landraces with and without VT3Pro traits across germplasm.

\section{Genetic segregation analysis}

Chi square analysis was performed at a 5\% level of significance to determine the segregation of the MON 88017 and MON 89034 genes for the four evaluated generations. The Chi square analysis was based on comparing the observed to the expected segregation ratio per Mendelian principles. Expected ratios for plants with and without transgenes for $\mathrm{BC} 1$, $\mathrm{BC} 2$, and $\mathrm{BC} 3$ generations was 1:1 for a single gene, or $1: 1: 1: 1$ when both genes are considered. Expected ratios for $\mathrm{BC} 3 \mathrm{~F} 2$ generations was 3:1 for a single gene, or 9:3:3:1 when both genes are considered. The Chi square analysis was completed for each landrace, as well as across landraces (which contributed to increased sample size).

\section{Results}

Results from this study indicated similarity between landraces with and without VT3Pro traits, and diversity among reference and control landraces for the evaluated characteristics. The considered observations included: descriptive and phenotypic characteristics, plant responses to stressors, and kernel compositional characteristics.

\section{Descriptive characteristics}

Tuxpeño with and without VT3Pro traits showed comparable values for the evaluated descriptive characteristics: proportion of plants with white $(67.8 \%$ vs. $60 \%$, respectively) and red tassels (32.2\% vs. $40 \%)$, white cobs $(99.7 \%$ vs. $100 \%)$, and white kernels (90.3\% vs. $82.7 \%$ ) (Table 1). Similarly, Tabloncillo with and without VT3Pro had comparable values for the evaluated descriptive characteristics, namely predominantly white tassels ( $85.6 \%$ vs. $81.1 \%)$, white cobs $(99.4 \%$ vs. $100 \%)$, and white kernels $(75.9 \%$ vs. $76.5 \%$ ) (Table 1).

In contrast to similarities observed for landraces with and without VT3Pro traits, there were some differences between Tuxpeño and Tabloncillo landraces used as controls in this study such as the proportion of white tassels $(60.0 \%$ vs. $81.1 \%$, respectively), or proportion of ears with yellow kernels ( $15.4 \%$ vs. $21.9 \%$, respectively) (Table 1 ). Diversity was also observed among landraces used as reference materials in this study. The proportion of plants with white tassels ranged from $88.1 \%$ for Chalqueño to as low as $28.8 \%$ for Blando/Blandito. Plants with white cobs ranged from $100 \%$ for Tuxpeño Sonora 51, Conico Norteño, Celaya 9, and Vandeño/Bandeño to $84.0 \%$ for Blando/Blandito. The proportion of white color kernels on an ear ranged from $99.4 \%$ for Celaya 9 to as low as 3.7\% for Vandeño/Bandeño. Ears with yellow kernels ranged from $95.0 \%$ for Vandeño/ Bandeño all the way to $0 \%$ for Blando/Blandito and Celaya 9, whereas ears with red kernels ranged from $12.0 \%$ for Blando/Blandito to $0 \%$ for Onaveño (Table 1). 
Phenotypic observations

The across-site analysis performed on 22 phenotypic characteristics indicated that there were no significant differences between landraces with and without VT3Pro traits for any of the evaluated characteristics except number of rows per ear (Table 2). However, the differences were less then the unit of measurement, thus considered too small to be biologically meaningful (13.7 vs. 13.2 for Tuxpeño and 11.8 vs. 11.7 across landraces).

In contrast to similarities observed between landraces with and without VT3Pro traits, there were significant differences detected between Tuxpeño and Tabloncillo landraces used as controls in this study for a number of characteristics, including days to anthesis (72.6 vs. 68.0$)$, ear height (122.1 vs. $110.4 \mathrm{~cm})$, plant height (216.1 vs. $201.0 \mathrm{~cm}$ ), stalk lodging (5.8 vs. 11.4 plants), ear length (16.9 vs. $18.4 \mathrm{~cm})$, ear diameter ( 4.3 vs. $3.8 \mathrm{~cm}$ ), cob diameter ( 2.6 vs. $2.3 \mathrm{~cm})$, kernel depth (17.5 vs. $14.7 \mathrm{~mm}$ ), rows per ear (13.2 vs 10.2), and kernels per ear (371.9 vs. 275.4) (Table 2).

Furthermore, landraces used as references in this study have shown a broad range of values for many of the evaluated characteristics such as days to anthesis and silking, number of tassel branches, ear and plant height, kernel depth, rows per ear, kernels per ear, and yield (Table 2).

Table 2 Mean value for phenotypic characteristics of landraces with and without VT3Pro traits in 2015 and 2016 field trials

\begin{tabular}{|c|c|c|c|c|c|c|c|}
\hline \multirow[t]{2}{*}{ Phenotypic characteristic (unit) } & \multicolumn{2}{|l|}{ Tuxpeño } & \multicolumn{2}{|c|}{ Tabloncillo } & \multicolumn{2}{|c|}{ Across landraces } & \multirow[t]{2}{*}{ Reference range $^{\mathrm{a}}$} \\
\hline & VT3Pro & Control & VT3Pro & Control & VT3Pro & Control & \\
\hline Early stand count & 59.4 & 58.2 & 62.9 & 60.1 & 61.1 & 59.1 & $48.0-75.5$ \\
\hline Days to anthesis ${ }^{b}$ & 74.5 & 72.6 & 68.3 & 68.0 & 71.4 & 70.3 & $57.8-107.3$ \\
\hline Days to silking & 77.6 & 75.3 & 70.7 & 70.9 & 74.2 & 73.1 & $57.5-117.8$ \\
\hline Tassel length (cm) & 37.7 & 36.7 & 36.7 & 36.1 & 37.2 & 36.6 & $32.5-42.3$ \\
\hline Tassel branches/plant & 15.3 & 14.6 & 14.1 & 13.3 & 14.7 & 13.9 & $8.8-19.9$ \\
\hline Stay-green (1-9 scale) & 5.6 & 6.1 & 7.0 & 6.1 & 6.3 & 6.3 & $2.0-8.0$ \\
\hline Ear height $(\mathrm{cm})^{\mathrm{b}}$ & 124.1 & 122.1 & 110.3 & 110.4 & 117.2 & 116.3 & $96.6-205.8$ \\
\hline Plant height $(\mathrm{cm})^{\mathrm{b}}$ & 217.1 & 216.1 & 194.4 & 201.0 & 205.9 & 208.6 & $181.5-281.9$ \\
\hline Dropped ears ${ }^{c}$ & 0.1 & 0.1 & 0.1 & 0.1 & 0.1 & 0.1 & $0.0-0.5$ \\
\hline Stalk lodged plants ${ }^{\mathrm{b}}$ & 9.2 & 5.8 & 13.0 & 11.4 & 11.1 & 8.6 & $0.0-14.3$ \\
\hline Root lodged plants & 2.8 & 3.0 & 2.8 & 3.0 & 2.8 & 3.0 & $1.5-8.8$ \\
\hline Final stand count & 47.4 & 45.1 & 48.9 & 46.8 & 48.2 & 46.0 & $35.8-61.0$ \\
\hline Ear length $(\mathrm{cm})^{\mathrm{b}}$ & 16.5 & 16.9 & 18.5 & 18.4 & 17.5 & 17.7 & $12.1-20.7$ \\
\hline Ear diameter $(\mathrm{cm})^{\mathrm{b}}$ & 4.3 & 4.3 & 3.7 & 3.8 & 4.0 & 4.1 & $2.8-4.3$ \\
\hline Cob diameter $(\mathrm{cm})^{\mathrm{b}}$ & 2.6 & 2.6 & 2.2 & 2.3 & 2.4 & 2.5 & $2.0-2.7$ \\
\hline Kernel depth $(\mathrm{mm})^{\mathrm{b}}$ & 16.9 & 17.5 & 15.0 & 14.7 & 16.0 & 16.1 & $5.5-21.7$ \\
\hline Rows/ear ${ }^{\mathrm{b}}$ & $13.7 *$ & 13.2 & 9.8 & 10.2 & $11.8^{*}$ & 11.7 & $9.4-12.6$ \\
\hline Kernels/ear ${ }^{\mathrm{b}}$ & 365.9 & 371.9 & 280.5 & 275.4 & 323.2 & 323.7 & $41.4-338.1$ \\
\hline 100-kernel weight $(\mathrm{g})$ & 29.0 & 30.0 & 32.8 & 32.3 & 31.1 & 30.9 & $20.0-35.1$ \\
\hline Grain moisture (\%) & 18.9 & 16.3 & 16.0 & 15.1 & 17.4 & 15.7 & $13.9-26.4$ \\
\hline Test weight (kg/hl) & 70.7 & 71.2 & 69.7 & 71.2 & 70.2 & 71.2 & $55.3-71.8$ \\
\hline Yield (Mg/ha) & 2.8 & 3.1 & 2.6 & 2.4 & 2.7 & 2.7 & $0.2-3.1$ \\
\hline
\end{tabular}

*Indicates statistically significant difference between VT3Pro landrace and the control $(\alpha=0.05)$

${ }^{a}$ Reference range is calculated from the minimum and maximum mean values among 10 unique reference materials

${ }^{\mathrm{b}}$ Characteristics that showed statistically significant differences between Tuxpeño control and Tabloncillo control entries $(\alpha=0.05)$

${ }^{\mathrm{c}}$ No statistical comparisons were made for dropped ears due to a lack of variability 
Table 3 Mean value for kernel compositional characteristics of landraces with and without VT3Pro traits in 2015 and 2016 field trials

\begin{tabular}{|c|c|c|c|c|c|c|c|}
\hline \multirow[t]{2}{*}{ Compositional characteristic (unit) } & \multicolumn{2}{|l|}{ Tuxpeño } & \multicolumn{2}{|c|}{ Tabloncillo } & \multicolumn{2}{|c|}{ Across landraces } & \multirow[t]{2}{*}{ Reference range $^{\mathrm{a}}$} \\
\hline & VT3Pro & Control & VT3Pro & Control & VT3Pro & Control & \\
\hline \multicolumn{8}{|l|}{ Proximate analytes (\% dw) } \\
\hline Protein & 12.70 & 13.04 & 12.67 & 12.94 & 12.69 & 12.99 & $12.49-14.23$ \\
\hline Total Fat & 4.58 & 4.50 & 4.72 & 4.64 & 4.65 & 4.57 & $4.05-5.06$ \\
\hline Ash & 1.53 & 1.51 & 1.55 & 1.57 & 1.54 & 1.54 & $1.42-1.88$ \\
\hline Carbohydrates (calculation) & 81.21 & 80.97 & 81.07 & 80.85 & 81.14 & 80.91 & $79.01-81.65$ \\
\hline \multicolumn{8}{|l|}{ Phenolics $(\mu g / g d w)$} \\
\hline Ferulic acid (bound) ${ }^{\mathrm{b}, \mathrm{c}}$ & 1.99 & 1.93 & $1.49 *$ & 1.77 & $1.74 *$ & 1.85 & $1.15-2.53$ \\
\hline Ferulic acid (free) & 66.75 & 70.75 & 83.29 & 87.86 & 74.75 & 79.30 & $55.63-123.61$ \\
\hline$p$-Coumaric acid (bound) & 144.46 & 141.18 & 93.92 & 119.35 & 119.19 & 130.27 & $101.93-236.21$ \\
\hline$p$-Coumaric acid (free) & 8.07 & 7.10 & 7.30 & 6.61 & 7.69 & 6.85 & $0.50-20.23$ \\
\hline \multicolumn{8}{|l|}{ Soluble carbohydrates ( $\% d w)$} \\
\hline Sucrose & 2.00 & 1.69 & 1.89 & 1.90 & 1.95 & 1.80 & $1.09-2.19$ \\
\hline Fructose $^{\mathrm{b}}$ & $0.040 *$ & 0.029 & 0.038 & 0.044 & 0.039 & 0.037 & $0.037-0.073$ \\
\hline Glucose & 0.14 & 0.13 & 0.12 & 0.14 & 0.13 & 0.14 & $0.08-0.18$ \\
\hline
\end{tabular}

*Indicates statistically significant difference between VT3Pro landrace and the control $(\alpha=0.05)$

${ }^{a}$ Reference range is calculated from the minimum and maximum mean values among the unique reference materials

${ }^{\mathrm{b}}$ Characteristics that showed statistically significant differences between Tuxpeño control and Tabloncillo control entries $(\alpha=0.05)$

${ }^{\mathbf{c}}$ Expressed in $\mathrm{mg} / \mathrm{g} \mathrm{dw}$

Responses to abiotic and biotic stressors

The across-site stressor assessments included 139 observations (48 abiotic, 35 arthropod, and 56 disease) which did not result in any biologically meaningful differences between landraces with and without the VT3Pro traits (S-Table 3). For the abiotic stressors, no differences were observed between VT3Pro landraces and their respective controls for any of the comparisons except for Tabloncillo VT3Pro that showed lower wind damage compared to the control at the AZ2015 site (slight vs. moderate rating, respectively). For arthropod stressors, no differences were observed between landraces with and without VT3Pro traits for any of the comparisons. Likewise, despite differences observed for gray leaf spot between landraces with and without VT3Pro traits at the AZ-2015 site (none vs. slight rating, respectively), no differences were observed for any of the other disease comparisons (S-Table 3). All VT3Pro landrace responses to the abiotic and biotic stressors were within the response range of the evaluated reference landraces (data not shown).
Kernel composition

The across-site assessment for kernel composition included a total of 11 characteristics (four proximate analytes, four phenolics, and three soluble carbohydrates) (Table 3). The evaluation of proximate analytes encompasses major kernel components including protein, total fat, ash, and carbohydrates. In this study, no statistically significant differences were observed between landraces with and without VT3Pro traits for any evaluated proximate analyte (Table 3 ).

Major phenolic compounds in maize ( $p$-coumaric and trans-ferulic acid) in their soluble and cell-wall bound forms were also analyzed. A statistically significant difference was observed for bound ferulic acid between Tabloncillo with and without VT3Pro traits. This difference $(0.28 \mu \mathrm{g} / \mathrm{g} \mathrm{dw})$ is not biologically relevant when considering the much larger variability observed in the Tabloncillo control $(0.76-3.10 \mu \mathrm{g} / \mathrm{g} \mathrm{dw})$ and that observed among the references $(1.15-2.53 \mu \mathrm{g} / \mathrm{g} \mathrm{dw})$. Generally, the analyzed phenolic compounds showed a wide range of values among reference landraces, including free $p$ - 
coumaric acid with up to 40 -fold difference among the tested reference landraces (Table 3).

For the soluble carbohydrates analyzed (sucrose, glucose, and fructose) a statistically significant difference was observed for fructose between Tuxpeño with and without VT3Pro traits. The statistically significant difference is not relevant from a biological standpoint when considering the variation observed within the control (0.007-0.082\% dw) and that observed among the references $(0.037-0.073 \% \mathrm{dw})$ (Table 3). As expected, sucrose was the most abundant soluble sugar, followed by glucose and fructose.

\section{Genetic segregation analysis}

Four segregating generations $(\mathrm{BC} 1, \mathrm{BC} 2, \mathrm{BC} 3$, and BC3F2) were analyzed using single (MON 89034, MON 88017) and two-gene (MON $89034 \times$ MON 88017) models for VT3Pro landraces. The analysis was conducted for each landrace, as well as across the two landraces. None of the Chi square values were significantly different from expected in $\mathrm{BC} 1$ and $\mathrm{BC} 3 \mathrm{~F} 2$ generations (Table 4). Only one value deviated from the expected ratio in $\mathrm{BC} 2$ and

Table 4 Chi square segregation analyses of VT3Pro traits (MON 89034, MON 88017 and MON $89034 \times$ MON 88017) across four generations of two maize landraces

\begin{tabular}{lllll}
\hline Genes & $\mathrm{BC1}^{\mathrm{a}}$ & $\mathrm{BC2}^{\mathrm{a}}$ & $\mathrm{BC3}^{\mathrm{a}}$ & $\mathrm{BC3F}^{\mathrm{b}}$ \\
\hline MON 89034 & 1.31 & 0.16 & $4.83^{*}$ & 0.89 \\
MON 88017 & 0.96 & 0.52 & 2.31 & 0.09 \\
MON 89034 × MON & 2.69 & 1.00 & 7.60 & 0.85 \\
$\quad$ 88017 & & & & \\
Tabloncillo & & & & \\
MON 89034 & 0.71 & 0.16 & 1.07 & 0.27 \\
MON 88017 & 1.03 & $4.08^{*}$ & 1.91 & 0.12 \\
MON 89034 x MON 88017 & 3.14 & 4.78 & 3.73 & 1.21 \\
Across landraces & & & & \\
MON 89034 & 0.06 & 0.32 & 0.72 & 0.21 \\
MON 88017 & 0.00 & 3.75 & 0.01 & 0.00 \\
MON 89034 $\times$ MON & 0.18 & 4.91 & 0.74 & 0.23 \\
88017 & & & & \\
\hline
\end{tabular}

*Indicates statistically significant difference between observed and expected ratios using $\mathrm{Chi}$ square test statistic $(p$ value $<0.05)$

${ }^{\mathrm{a}}$ Expected ratios for $\mathrm{BC} 1, \mathrm{BC} 2$, and $\mathrm{BC} 3$ generations was $1: 1$ for a single gene, or 1:1:1:1 for both genes combined

${ }^{\mathrm{b}}$ Expected ratios for $\mathrm{BC} 3 \mathrm{~F} 2$ generations was 3:1 for a single gene, or 9:3:3:1 for both genes combined
BC3 generations each. However, when the analyses were done across landraces, which increased sample size, all the populations showed expected genetic ratios.

\section{Discussion}

Diversity within and among landraces

The entries evaluated in this study were chosen to represent 10 out of the 59 recognized races of maize in Mexico (Sanchez et al. 2000). Observed characteristics provided evidence for the genetic diversity within and among landraces (Tables 1, 2, 3). For example, each landrace showed variation in tassel color ranging from white to different shades of red. This variation is not surprising as Mexican farmers do not typically select for plant characteristics such as tassel color (Louette and Smale 1998). Furthermore, evaluated landraces had plants with mostly white cobs, although a low percentage of red cobs was also observed for some populations. Kernel color showed the most variability, with ears ranging from a uniform kernel color (white, yellow, or red) to those with kernels of different colors. Some of this variation is due to crosspollination by landraces grown in surrounding plots and xenia effect associated with this characteristic. However, most of the observed variability is due to diversity within landraces, considering that most kernels result from self- or sib-pollination even if grown in close proximity to a foreign pollen source (Baltazar et al. 2015).

These results confirm that the level of variation within a given landrace, very typical for Mexican open-pollinated maize populations (Sanchez et al. 2000), was maintained not only for reference landraces during seed increase, but also for the four entries developed during VT3Pro traits introgression (Tuxpeño VT3Pro, Tuxpeño control, Tabloncillo VT3Pro, and Tabloncillo control). Maintaining appropriate population size during backcrossing and selection along with employing sib-pollination for seed increase (mimicking open-pollination in farmers' field) contributed to the retention of variation within each entry evaluated in this study.

Diversity was also observed among the landraces evaluated in this study. This is not surprising as they originated from different ecoregions associated with 

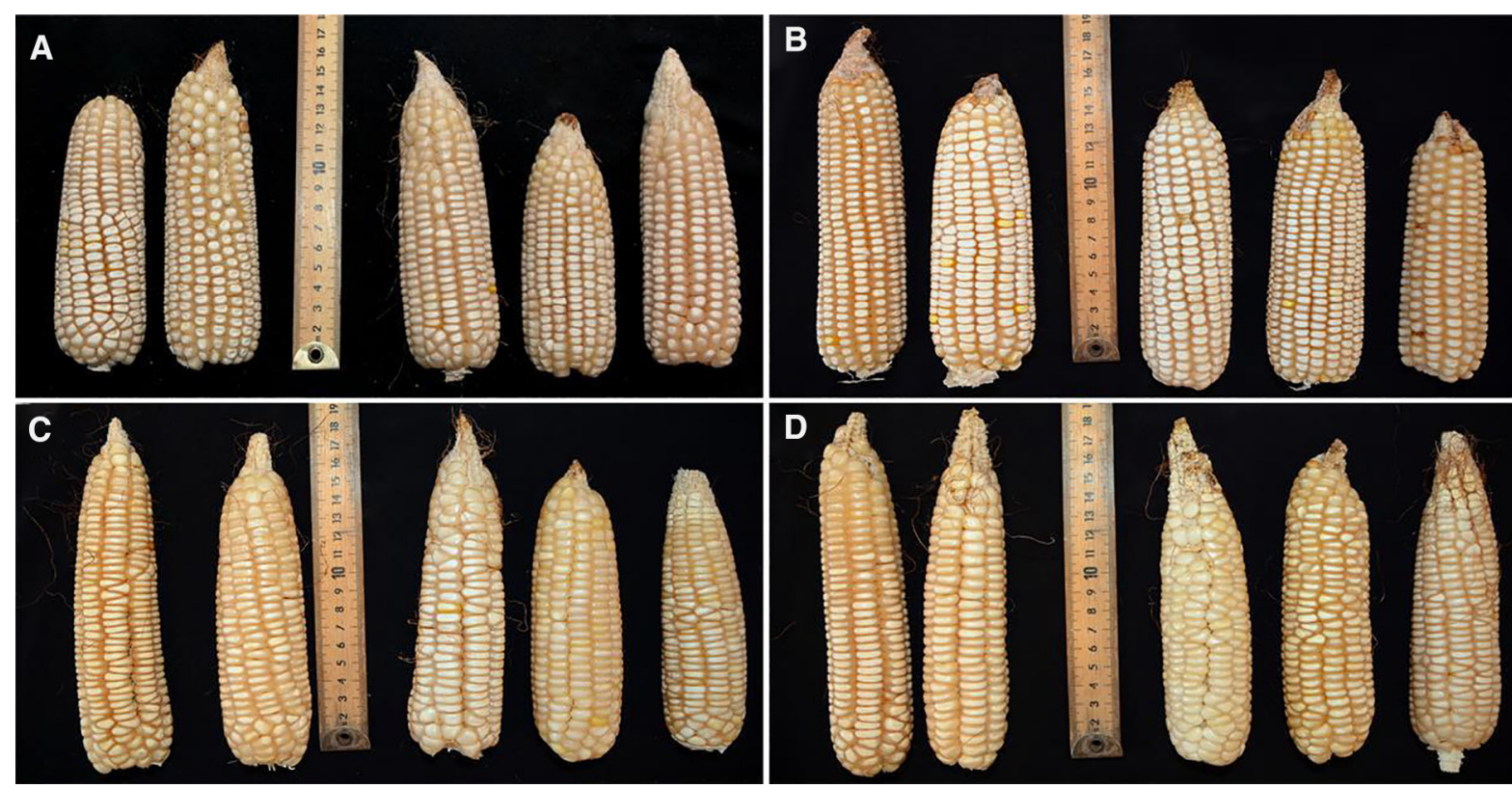

Fig. 1 Harvested ears from Tuxpeño VT3Pro (a), Tuxpeño control (b), Tabloncillo VT3Pro (c), and Tabloncillo control (d)

Mexican states of Sonora, Chihuahua, Sinaloa, Nayarit, Jalisco, Guanajuato, and Puebla. These seven states collectively represent one third of the total area of Mexico. The genetic diversity among these selected landraces is exemplified by descriptive characteristics like color of tassels, cobs, and kernels (Table 1), as well as phenotypic (Table 2), and compositional characteristics (Table 3). For example, wide ranges were observed for plant height $(181.5-281.9 \mathrm{~cm})$, ear length (12.1-20.7 cm), number of rows per ear (9.4-13.7), or p-coumaric acid (free) (0.50-20.23 mg/g dw) among the evaluated entries. Even landraces from the same region showed considerable diversity. For example, the proportion of plants with white tassels ranged from 62.5 to $85.6 \%$ for landraces that originated from Sonora, or from 58.8 to $85.6 \%$ for those from Nayarit. Similarly, the proportion of ears with white kernels ranged from 70.9 to $90.3 \%$ for entries from Sonora, or from 3.7 to $76.5 \%$ for those from Nayarit. This agrees with results reported in Pineda-Hidalgo et al. (2014) that showed high genetic diversity among maize landraces collected from a single state, even though the majority of the evaluated landraces were of either of Tuxpeño or Tabloncillo type.

The two landraces, Tuxpeño and Tabloncillo, which were used as controls in this study also showed differences in their performance, thus indicating that their identity and diversity was maintained through the process of material development for the field trials. Both landraces have predominantly white kernels, as this characteristic is generally preferred by Mexican farmers (Louette and Smale 1998), but the proportion of white kernels was higher for Tuxpeño (Table 1). Furthermore, Tabloncillo flowered a few days earlier, had shorter plants, longer ears, smaller ear and cob diameters, smaller kernel depth, and produced less kernels per ear compared to Tuxpeño (Table 2; Fig. 1). These results agree with the observations of Louette and Smale (1998) that landraces of Tabloncillo type are characterized by shorter plants, earlier maturity, and ears with fewer kernel rows. Similarly, Baltazar et al. (2005) showed that Tabloncillo flowered earlier compared to Tuxpeño.

\section{Landraces with and without VT3Pro}

This study was undertaken to assess if the introduction of VT3Pro traits into landrace varieties exhibit changes in their characteristics beyond the intended traits (insect protection and herbicide tolerance). To our knowledge, this was the first study that evaluated maize landraces with introgressed biotechnology traits. The two landraces, Tuxpeño and Tabloncillo, 
were chosen because they are widely grown in Mexico (Sanchez et al. 2000; Lazos and Chauvet 2012), have broad representation on both coasts of Mexico, and are distributed in areas with modern maize hybrid production (Lazos and Chauvet 2012). Furthermore, they are of diverse origin, have different phenotypes, and are used for different food products (Sanchez et al. 2000; Vazquez-Carrillo et al. 2017).

The two introgressed biotechnology traits (MON 89034 and MON 88017) have been approved for cultivation in countries such as Argentina, Brazil, Canada, Colombia, Honduras, Paraguay, Philippines, South Africa, and the USA (ISAAA 2018). Prior to commercialization, hybrid maize containing MON 89034 and MON 88017 as single traits as well as stacked together were extensively tested for safety. The results of rigorous environmental risk and food safety assessments conducted for each trait have supported the conclusion that these products are as safe for human consumption and the environment as conventional varieties (Prado et al. 2014). These studies, along with years of commercial cultivation and use of these products, are evidence of the safe and effective use of GM maize. This study was conducted to test the hypothesis that Mexican maize landraces would remain unchanged in their characteristics, except for the associated GM traits, in the unlikely event of inadvertent introgression of VT3Pro transgenes.

Generally, no difference in performance was observed between landraces with and without VT3Pro traits indicating that the insertion of VT3Pro traits did not influence the phenotypic characteristics evaluated in this study. Similarly, Heredia-Diaz et al. (2016) showed no significant differences between maize hybrids with and without VT3Pro traits for early stand count, days to silking, days to anthesis, root lodging, stalk lodging, dropped ears, and final stand count. They did find few differences in performance, mostly due to pressure from target insect pests which resulted in better plant health of maize hybrids with VT3Pro traits. Graeber et al. (1999) concluded that incorporation of the Bt gene had little, if any, effect on agronomic performance of maize hybrids except for intended insect protection. Similar observations have been made for other transgenes, regardless of whether they were incorporated into maize (Nakai et al. 2015; Sammons et al. 2014) or other crops (Horak et al. 2007, 2015a).
Generally, no differences were observed between landraces with and without the VT3Pro traits in terms of responses to abiotic and biotic stressors that are not associated with intended traits (insect protection and herbicide tolerance). Similar results were observed by Ahmad et al. (2015) who showed comparable abundance and damage from non-target arthropods between maize hybrids with and without insect protection and herbicide tolerance GM traits. Other studies have also showed comparable responses to stressors between crops with and without GM traits (Horak et al. 2007, 2015b).

Tuxpeño is predominantly used for tortilla making, whereas Tabloncillo is primarily utilized for specialty products (Vazquez-Carrillo et al. 2017), which explains why the value of these landraces is closely associated with kernel compositional characteristics. The introgression of VT3Pro traits into Tuxpeño and Tabloncillo landraces did not result in unexpected changes in kernel composition associated with proximate analytes, carbohydrate metabolism, or phenolic content that may contribute to the characteristics of the grain and consequently impact the quality of food products. These results are supported by previous studies, which demonstrated that composition is affected more by environment and germplasm than by transgene insertion (Drury et al. 2008; McCann et al. 2007; Venkatesh et al. 2015).

Segregation analyses, conducted across multiple generations, indicated that VT3Pro transgenes segregated following Mendelian principles. Our results agree with observations that transgenes are expected to segregate the same as any endogenous gene (Bellon and Berthaud 2004).

In summary, this study was conducted to address questions regarding performance and inheritance of GM traits if inadvertently introgressed into maize landraces. These results indicate that Mexican landraces with and without VT3Pro traits have comparable phenotypic characteristics, responses to stressors, and kernel compositional characteristics with transgenes segregating the same as any endogenous gene. Our conclusions indicate that results obtained for maize hybrids can be extrapolated to maize landraces. These results should be taken into consideration when discussing benefits and risks associated with commercial production of GM maize hybrids in the centers of origin and diversity of maize. 
Acknowledgements The authors are grateful to Juan Manuel Hernandez Casillas for technical assistance during material development, to Trever Jones and Randy Norton for managing the field trials, to Desiree Ochoa-Martínez and Cristina MezaMiranda for technical assistance with phenolic and carbohydrate analysis of grain samples, Sofia Escoto for GIS assistance and to Aniruddha Raychaudhuri, Greg Tilton, John Vicini, Erin Bell, Roger J. Effertz, and Sonya J. Franklin for reviewing the manuscript.

Open Access This article is distributed under the terms of the Creative Commons Attribution 4.0 International License (http:// creativecommons.org/licenses/by/4.0/), which permits unrestricted use, distribution, and reproduction in any medium, provided you give appropriate credit to the original author(s) and the source, provide a link to the Creative Commons license, and indicate if changes were made.

\section{References}

Ahmad A, Negri I, Oliveira W, Brown C, Asiimwe P, Sammons B, Horak M, Jiang C, Carson D (2015) Transportable data from non-target arthropod field studies and the environmental risk assessment of genetically modified maize expressiong an insecticidal double-stranded RNA. Transgenic Res. https://doi.org/10.1007/s11248-015-9907-3

Aragon-Cuevas F, Taba S, Castro-Garcia FH, HernandezCasillas JM, Cabrera-Toledo JM, Alcala LO, Ramirez ND (2005) In situ conservation and use of local maize races in Oaxaca, Mexico: a participatory and decentralized approach. In: Taba S (ed) Latin American maize Germpasm conservation: regeneration, in situ conservation, core subsets, and prebreeding; proceedings of a CIMMYT workshop, Mexico, April 2003, pp 26-38

Arteaga MC, Moreno-Letelier A, Mastretta-Yanes A, VazquezLobo A, Brena-Ochoa A, Moreno-Estrada A, Eguiarte LE, Pinero D (2016) Genomic variation in recently collected maize landraces from Mexico. Genomic Data 7:38-45

Ayala-Soto FE, Serna-Saldívar SO, García-Lara S, Pérez-Carrillo E (2014) Hydroxycinnamic acids, sugar composition and antioxidant capacity of arabinoxylans extracted from different maize fiber sources. Food Hydrocolloids 35:471-475. https://doi.org/10.1016/j.foodhyd.2013.07. 004

Baltazar BM, de Jesus Sanchez-Gonzalez J, de la Cruz-Larios L, Schoper JB (2005) Pollination between maize and teosinte: an important determinant of gene flow in Mexico. Theor Appl Genet 110:519-526

Baltazar BM, Castro Espinoza L, Espinoza Banda A, de la Fuente Martínez JM, Garzón Tiznado JA, González García $\mathrm{J}$ et al (2015) Pollen-mediated gene flow in maize: implications for isolation requirements and coexistence in Mexico, the center of origin of maize. PLoS ONE 10:e0131549

Bellon MR, Berthaud J (2004) Transgenic maize and the evolution of landrace diversity in Mexico. The importance of farmers' behavior. Plant Physiol 134:883-888
Brookes G, Barfoot P (2018a) Environmental impacts of genetically modified (GM) crop use 1996-2016: impacts on pesticide use and carbon emissions. GM Crops Food. https://doi.org/10.1080/21645698.2018.1476792

Brookes G, Barfoot P (2018b) Farm income and production impacts of using GM crop technology 1996-2016. GM Crops Food 9(2):59-89. https://doi.org/10.1080/21645698. 2018.1464866

Brush SB (1995) In situ conservation of landraces in centers of crop diversity. Crop Sci 35:346-354

Castillo Gonzalez F, Goodman MM (1995) Research on gene flow between improved maize and landraces. In: Serratos JA, Willcox MC, Castillo F (eds) Gene flow among maize landraces, improved maize varieties, and teosinte: implication for transgenic maize. El Batan, Mexico

Chambers KJ, Brush SB, Grote MN, Gepts P (2007) Describing Maize (Zea mays L.) landrace persistence in the Bajio of Mexico: a survey of 1940s and 1950. Collecion Locations. Econ Bot 61(1):60-72

Corrales MJL, Martinez CJL, Ozuma MMB, Duran PHA, Escobedo JA, Quinones FJ, Garzon TJA, Castro EL, Zavala GF, Espinoza BA, Gonzalez GJ, Jiang C, Brown RC, de la Fuente MJM, Heredia DO, Whitsel EJ, Asiimwe P, Baltazar MB, Ahmad A (2018) Transportability of NTA field data for the use in ERA of GM maize in Northern Mexico. J Appl Entomol 2018:1-14. https://doi.org/10. 1111/jen.12499

Drury SM, Reynolds TL, Ridley WP, Bogdanova N, Riordan S, Nemeth MA, Sorbet R, Trujillo WA, Breeze ML (2008) Composition of forage and grain from second-generation insect-protected corn MON 89034 is equivalent to that of conventional corn (Zea mays L.). J Agric Food Chem $56: 4623-4630$

Espinosa A, Sierra M, Gómez N (2003) Producción y tecnología de semillas mejoradas de maíz por el INIFAP en el escenario sin la PRONASE. Agron Mesoamericana $14: 117-121$

FAOSTAT (2016) Statistical databases and data-sets of the Food and Agriculture Organization of the United Nations. http://www.fao.org/faostat/en/\#data/QC. Accessed Oct 2018

Fernandez-Suarez R, Morales-Chavez LA, Galvez Mariscal A (2013) Importance of mexican maize landraces in the national ties. An essential review. Rev Fitotec Mex 36:275-283

FIRA (2016) Panorama Agroalimentario-Maiz 2016. Direccion de Investigacion y Evaluacion Economica y Sectorial. Gobierno de Mexico. https://www.gob.mx/cms/uploads/ attachment/file/200637/Panorama_Agroalimentario_Ma_ z_2016.pdf. Accessed Oct 2018

Graeber JV, Nafziger ED, Mies DW (1999) Evaluation of transgenic, Bt-containing corn hybrids. J Prod Agric 12:659-663

Harrigan GG, Ridley WP, Miller KD, Sorbet R, Riordan SG, Nemeth MA et al (2009) The forage and grain of MON 87460, a drought-tolerant corn hybrid, are compositionally equivalent to that of conventional corn. J Agric Food Chem 57:9754-9763

Heredia Diaz O, Aldaba Meza JL, Baltazar BM, Bojorquez Bojorquez G, Castro Espinoza L, Corrales Madrid JL, de la Fuente Martinez JM, Duran Pompa HA, Escobedo JA, 
Espinoza Banda A, Garzon Tiznado JA, Gonzalez Garcia J, Guzman Rodriguez JL, Madueno Martinez JI, Martinez Carrillo JL, Meng C, Quinones Pando FJ, Rosales Robles E, Ruiz Hernandez I, Trevino Ramirez JE, Uribe Montes HR, Zavala Garcia F (2016) Plant characterization of genetically modified maize hybrids MON-89034$3 \times$ MON-88017-3, MON-89034-3 × MON-OO603-6, and MON-00603-6: alternatives for maize production in Mexico. Transgenic Res 26:135-181. https://doi.org/10. 1007/s11248-016-9991-z

Heredia-Olea E, Pérez-Carrillo E, Serna-Saldívar SE (2012) Effects of different acid hydrolyses on the conversion of sweet sorghum bagasse into C5 and C6 sugars and yeast inhibitors using response surface methodology. Biores Technol 119:216-223

Horak MJ, Rosenbaum EW, Woodrum CL, Martens AB, Mery RF, Cothren JT et al (2007) Characterization of roundup ready flex cotton, 'MON 88913', for use in ecological risk assessment: evaluation of seed germination, vegetative and reproductive growth, and ecological interactions. Crop Sci 47:268-277

Horak MJ, Rosenbaum EW, Kendrick DL, Sammons B, Phillips SL, Nickson TE, Dobert RC, Perez T (2015a) Plant characterization of Roundup Ready 2 Yield $^{\circledR}$ soybean, MON 89788 , for use in ecological risk assessment. Transgenic Res 24:213-225

Horak MJ, Rosenbaum EW, Phillips SL, Kendrick DL, Carson D, Clark PL, Nickson TE (2015b) Characterization of the ecological interactions of Roundup Ready 2 Yield $^{\circledR}$ soybean, MON 89788, for use in ecological risk assessment. GM Crops Food 6(3):167-182. https://doi.org/10.1080/ 21645698.205.1067365

ISAAA (2016) Global status of commercialized biotech/GM crops: 2016. ISAAA Brief No 52. Ithaca, NY, USA

ISAAA (2018) GM approval database. http://www.isaaa.org/ gmapprovaldatabase/. Accessed 3 Oct 2018

Lazos E, Chauvet M (2012) Análisis del contexto social y biocultural de las colectas de maíces nativos en México. Projecto Global de Maices, Informe de Gestion. CONABIO, Mexico. https://www.biodiversidad.gob.mx/genes/ pdf/analisis_socio_cultural_maices.pdf

Louette D, Smale M (1998) Farmers' seed selection practices and maize variety characteristics in a traditionally-based Mexican community. CIMMYT Economics Working Paper No 98-04. Mexico, D.F., pp 1-27

Matsuoka Y, Vigouroux Y, Goodman MM, Sanchez JG, Buckler E, Doebley J (2002) A single domestication for maize shown by multilocus microsatellite genotyping. PNAS USA 99:6080-6084

McCann MC, Trujillo WA, Riordan SG, Sorbet R, Bogdanova NN, Sidhu RS (2007) Comparison of the forage and grain composition from insect-protected and glyphosate-tolerant MON 88017 corn to conventional corn (Zea mays L.). J Agric Food Chem 55:4034-4042

Nakai S, Hishikawa K, Shimono A, Ohsawa R (2015) Transportability of confined field trial data from cultivation to import countries for environmental risk assessment of genetically modified crops. Transgenic Res 24:929-944. https://doi.org/10.1007/s11248-015-9892-6
Ortega Paczka RA (1973) Variacion en maiz y combios socioeconomicos en Chiapas, Mex. 1946-1971. M.S. thesis. College of Postgraduates, Chapingo, Mexico

Ortiz-Garcia S, Ezcurra E, Schoel B, Acevedo F, Soberon J, Snow AA (2005) Absence of detectable transgenes in local landraces of maize in Oaxaca, Mexico (2003-2004). PNAC 102:12338-12343

Phipps RH, Park JR (2002) Environmental benefits of genetically modified crops: global and European perspectives on their ability to reduce pesticide use. J Anim Feed Sci 11:1-18

Pineda-Hidalgo KV, Mendez-Marroquin KP, Vega Alvarez E, Chavez-Ontiveros J, Sanchez-Pena P, Garzon-Tiznado JA, Vega-Garcia MO, Lopez-Valenzuela JA (2014) Microsatellite-based genetic diversity among assessions of maize landraces from Sinaloa in Mexico. Hereditas 150:53-59. https://doi.org/10.1111/j.1601-5223.2013. 00019.x

Prado RJ, Segers G, Voelker T, Carson D, Dobert R, Phillips J, Cook K, Cornejo C, Monken J, Grapes L, Reynolds T, Martino-Catt S (2014) Genetically engineered crops: from idea to product. Annu Rev Plant Biol 65:769-790. https:// doi.org/10.1146/annurev-arplant-050213-040039

Ridley WP, Harrigan GG, Breeze ML, Nemeth MA, Sidhu RS, Glenn KC (2011) Evaluation of compositional equivalence for multitrait biotechnology crops. J Agric Food Chem 59:5865-5876

SAGARPA (2017) Maíz grano blanco y amarillo Mexicano. Planeación Agrícola Nacional 2017-2030. https://www. gob.mx/cms/uploads/attachment/file/256429/B_sico-Ma_ z_Grano_Blanco_y_Amarillo.pdf. Accessed Oct 2018

Sammons B, Whitsel J, Stork LG, Reeves W, Horak M (2014) Characterization of drought-tolerant maize MON 87460 for use in environmental risk assessment. Crop Sci 54:719-729

Sanchez JJG, Goodman MM, Stuber CW (2000) Isozymatic and morphological diversity in the races of maize of Mexico. Econ Bot 54(1):45-59

Shiferaw B, Prasanna BM, Hellin J, Bänziger M (2011) Crops that feed the world 6. Past successes and future challenges to the role played by maize in global food security. Food Secur 3:307. https://doi.org/10.1007/s12571-011-0140-5

Troyer AF (2006) Adaptedness and heterosis in corn and mule hybrids. Crop Sci 46:528-543

Vazquez-Carrillo MG, Perez-Camarillo JP, Hernandez-Casillas JM, Marrufo-Diaz MDL, Martinez-Ruiz E (2010) Calidad de grano y de tortillas de maices criollos del altiplano y valle del mezquital, Mexico. Revista Fitotecnia Mexicana 33(4):49-56

Vazquez-Carrillo MG, Santiago-Ramos D, Dominguez-Rendon E, Audelo-Benites MA (2017) Effects of two different Pozole preparation processes on quality variables and pasting properties of processed maize grain. J Food Qual. https://doi.org/10.1155/2017/8627363

Venkatesh TV, Cook K, Liu B, Perez T, Willse A, Tichich R, Feng P, Harrigan GG (2015) Compositional differences between near-isogenic GM and conventional maize hybrids are associated with backcrossing practices in conventional breeding. Plant Biotechnol J 13:200-210. https://doi.org/10.1111/pbi.12248 
Wang L, Beissinger TM, Lorant A, Ross-Ibara C, Ross-Ibarra J, Hufford MB (2017) The interplay of demography and selection during maize domestication and expansion. Genomic Biol 18:215. https://doi.org/10.1186/s13059017-1346-4

Wiken E, Jiménez Nava F, Griffith G (2011) North American terrestrial ecoregions-level III. Commission for Environmental Cooperation, Montreal
Zavala-López M, García-Lara S (2017) An improved microscale method for extraction of phenolic acids from maize. Plant Methods 13:81. https://doi.org/10.1186/s13007-0170235-x

Publisher's Note Springer Nature remains neutral with regard to jurisdictional claims in published maps and institutional affiliations. 